\title{
Creating an Interactive Classroom: Enhancing Student Engagement and Learning in Political Science Courses
}

\author{
Jonathan D. Mott
}

Danny Damron

Follow this and additional works at: https://scholarsarchive.byu.edu/facpub

Part of the Political Science Commons

\section{Original Publication Citation}

Danny Damron \& Jonathan D. Mott. 25. "Creating an Interactive Classroom: Enhancing Student Engagement \& Learning in Political Science Courses," Journal of Political Science Education, Fall Issue.

\section{BYU ScholarsArchive Citation}

Mott, Jonathan D. and Damron, Danny, "Creating an Interactive Classroom: Enhancing Student Engagement and Learning in Political Science Courses" (2005). Faculty Publications. 361.

https://scholarsarchive.byu.edu/facpub/361 


\title{
Interactive Voting Technology: \\ Enhancing Student Engagement \& Learning in Political Science Courses
}

\author{
Danny Damron, Brigham Young University \\ 745 SWKT \\ Department of Political Science \\ Brigham Young University \\ Provo, UT 84602 \\ danny damron@byu.edu \\ 801.422 .6690
}

Danny Damron is an adjunct professor in the Department of Political Science at Brigham Young University. He teaches courses on comparative politics, democratic transitions, East Asian politics. He is currently researching the relationship between civic group activism and democratic reform in East Asia.

$$
\begin{gathered}
\text { Jonathan Mott, Brigham Young University } \\
3800 \text { HBLL } \\
\text { Center for Instructional Design } \\
\text { Brigham Young University } \\
\text { Provo, UT 84602 } \\
\text { jonmott@byu.edu } \\
801.422 .1363
\end{gathered}
$$

Jonathan Mott is the Director of the Center for Instructional Design and an adjunct professor in the department of political science at Brigham Young University. He teaches courses in American government and public policy. 


\section{Abstract}

Students of the pedagogy of teaching have found that cooperative/problem-based learning activities engage the learner, promote ownership of the material, advance the development of higher-level cognitive skills, and increase retention better than more passive learning activities. Despite broad recognition within the political science discipline that classroom activities can and should facilitate better student learning outcomes, political science classes (both large and small) frequently have characteristics that make cooperative/problem-based learning activities more difficult to employ and less likely to succeed. Anonymity in large sections, a steep learning curve of complex concepts, and students who see passivity as the least costly approach to success combine to produce these sub-par learning outcomes. Recent developments in classroom technology, however, facilitate the use of cooperative learning techniques in a wide variety of political science classroom settings. In this article, we first explore the challenges associated with promoting student engagement in political science classes. Second, we review solutions to these challenges in the instructional psychology and technology literature. Finally, we describe specific tools and techniques professors can use to promote greater student engagement in their courses. In doing so, we draw on our own recent experiences with interactive voting technology in introductory political science courses at Brigham Young University. We also make suggestions about other class venues where similar technology could be employed. 
Scholars of educational psychology have long argued that students "learn what they do and not what we tell them" (Dewey 1963). Indeed, scholars have found that cooperative/problem-based learning activities engage the learner, promote ownership of the material, and advance the development of higher-level cognitive skills better than more passive learning activities. In addition, studies have found that problem-based learning activities result in dramatic increases in student retention of course material. As one noted scholar in the field has observed:

Cognitive science also tells us that the brain's activity is in direct proportion to its engagement with actively stimulating environments.... Maximum learning tends to occur when people are confronted with specific, identifiable problems that they want to solve and that are within their capacity to do so (Ewell, 1997).

At least some of the improvement in student learning outcomes is due to the reality that different students learn in different ways. By providing a wider variety of more engaging learning experiences for students, the instructor improves the chances of success for each student in a course (see Cromwell 1993; Steinert and Snell 1999).

Many political scientists have responded to these research findings by incorporating a wider variety of learning experiences into their teaching to reach their students more effectively. Recent articles in $P S$, for example, have highlighted ways that political science professors can motivate and enliven their students' learning experiences through cooperative/problem-based learning techniques. For example, Fox and Ronkowski advocate designing instruction that is sensitive to students' different learning styles to allow "students to make use of their strengths and not be unduly hampered by their learning weaknesses" $(1997,732)$. Likewise, Brock and Cameron note that through use of Kolb's Learning Preference Model, professors can counter learning preference mismatches between professor and student, thereby stimulating 
"students...to develop and build all the skills necessary for effective thinking and problem solving" $(1999,255)$. Payerhin points out that connecting students to the real world through case studies "provides the opportunity to investigate an issue in its natural complexity of interrelated factors and problems rather than in abstract form" (2003, 444). Finally, Ambrosio reported that student participation in an interactive classroom simulation on constitutional design enhanced learning and deepened understanding of complex issues (2004).

Despite broad recognition within the discipline that classroom activities can and should facilitate better student learning outcomes, political science classes (especially large introductory classes) frequently have characteristics that make cooperative/problem-based learning activities more difficult to employ and less likely to succeed. Anonymity in large sections, a steep learning curve of complex concepts, and students who see passivity as the least costly approach to success combine to produce these sub-par learning outcomes.

Recent developments in classroom technology, however, facilitate the use of cooperative learning techniques in both large and small classrooms. In this article, we first explore the challenges associated with promoting student engagement in large, introductory political science classes. Second, we review solutions to these challenges in the instructional psychology and technology literature. Finally, we describe specific tools and techniques professors can use to promote greater student engagement in large and small, introductory and advanced level classes. In doing so, we draw on our own recent experiences with interactive voting technology in introductory political science courses at Brigham Young University.

\section{The Problem}

Ultimately, the task in all political science classes is to teach the students to think critically about key concepts and ideas rather than just play the game of demonstrating that they 
can define those concepts and ideas. It is generally assumed that by the time students get to their upper-level classes, they are ready to begin practicing higher-level thinking skills. It is our contention however, that students are not only capable of higher level thinking but that it is a skill that must be practiced starting in introductory courses and continued throughout the course of undergraduate study. Students who think critically can employ political science concepts to analyze and evaluate competing explanations of political events and become more comfortable with the reality of partial answers to difficult and complex questions. In moving beyond playing "the game" of learning, professors can engage all levels of students in critical discussions and cooperative/problem-solving activities. Carefully designed activities, as many authors in PS and elsewhere have noted, can push students to move beyond simply demonstrating comprehension to analyzing the usefulness of that information (Steinert and Snell 1999). However, when expanded class size combines with the requirement that students master a number of complex concepts, and when students in class typically choose lower cost strategies leading to success (a good grade), cooperative/problem-solving classroom activities become much less practical and much less likely to succeed in promoting higher-level thinking.

Despite the imperative to design instruction based on cooperative learning methods, the reality of teaching political science in a variety of contexts presents a number of constraints. First, professors must often limit participation in order to cover the substantial amount of material included in any political science course. This most often means that communication is one-way — from professor to student — with students spending most of their time taking notes rather than engaging with the material. One-way communication also makes it more difficult for the professor to assess whether students understand the concepts. A few students may ask questions, or be called upon by the professor to answer questions, but by and large, student 
verbal participation must be limited so the instructor can cover the planned subject matter (Steinert and Snell 1999).

Second, while the professor may take the time to model higher-level thinking skills such as analysis and evaluation, it is generally impractical for the professor to provide time for students to practice these skills in class and provide immediate and individualized feedback. The problem then is that although the professor may expect students to move beyond lower-level thinking to higher-level thinking, the students may be incapable of making that move on their own. As Leamnson notes, "we may believe that students are learning to think, and are practicing doing it, but most are simply studying for the exam" $(1999,41)$. In the end, students may make the misplaced assumption that knowledge acquisition and comprehension means mastery and that they best achieve mastery through passively taking notes.

Third, because of either large student numbers or lecture-dominant teaching ${ }^{1}$, students can remain relatively anonymous, isolated, and consequently little involved in the knowledgebuilding process. As we noted previously, class management constraints limit interaction between professor and student and between students. Coming to class unprepared to discuss the material results in no penalty when one is anonymous and when there is little public incentive (a commitment to participate in a group activity related to the topic, for example) to know the material. In these circumstances, students may perceive themselves as playing a minor role in the knowledge-building process. In addition, large student numbers and lecture-dominant teaching

\footnotetext{
${ }^{1}$ It is important to point out that there is nothing inherently wrong with lecturing as a method of presenting material. In fact, lecturing remains an important technique in many of our classrooms. Rather than the sole method of teaching however, we argue that lecturing should play a complementary role with other teaching and learning experiences.
} 
do not facilitate interaction with others in the classroom, which makes students much less likely to take responsibility for their own learning. In the end, large class size and classes heavily reliant on lectures for material delivery often mean that students have little opportunity to talk about, collectively process, and apply the information they receive.

In addition to the atmosphere of anonymity and isolation, the challenge of learning a large number of difficult, complex, and abstract concepts makes the acquisition of higher-level thinking skills difficult. Political science classes (and particularly introductory classes) are naturally filled with many facts and new concepts that students must master to successfully engage in analysis and discussion of political events. Although achieving mastery is a normal process that all students must go through, they often become so consumed in memorization that they fail to see how those memorized facts and concepts should inform their understanding of the world around them. In other words, the students' efforts to reach the apex of a rather steep learning curve may end up as an end in itself rather than a means to deeper analysis and evaluation of the complex realities they experience.

In addition, because most students have little real-world experience or knowledge of the political world, they often struggle to connect those concepts to their reality and instead focus solely on knowledge acquisition and comprehension. Lecture-dominant class formats may contribute to this outcome as little opportunity to "test-drive" the concepts is available. In the end, the failure to connect concepts with "the world out there," means students' uninformed stereotypes about political life remain the most convenient source of explanation of the political world around them. On the one hand, students may be able to speak using the appropriate vocabulary but not be able to analyze. On the other hand, when the professor asks students to provide analysis of complex political situations, students are often frustrated by the (at best) 
partial answers and solutions that those concepts offer. The nature of the learning task and atmosphere and the students' inexperience leave them struggling to identify the significance of the concepts they learn, and they feel ill-prepared to connect those concepts to political realities. The ease of resorting to uninformed stereotypes offering less complex answers encourages students to shy away from analysis.

Like classroom size and content delivery, and conceptual complexity in political science classes, the balance of incentives associated with earning a grade may discourage students from acquiring analysis and evaluation skills. Like most of us, students are rational actors who seek the most benefit (in the students' case defined as a good grade and general education credit) at the lowest possible $\operatorname{cost}^{2}$; students have little interest in connecting with the material when much less effort may yield the same result. Thus, in-class passivity is often the best strategy. Passively listening, writing down everything the professor says, and then studying those notes prior to exams is often enough to get a "good grade." As a result, there is a strong disincentive to participate in class. ${ }^{3}$ As noted above, many students taking political science classes have had little exposure to the real world of politics — and what exposure they have had is often emotionally fraught. This means that venturing opinions in front of peers is often risky. In stating an opinion, students expose themselves to a discussion in which the validity of their opinion can

\footnotetext{
${ }^{2}$ This is certainly a controversial claim. We do not discount students' intrinsic desire to learn for learning sake. However, to ignore the role of cost (risking face in front of social peers, for example) and benefit (course grade) in a student's calculus of how much effort to expend in a given class would provide us with a narrow explanation of a much more complex decision.

${ }^{3}$ Leamnson seems to agree, noting that students" "modus operandi is to never attract attention to themselves, speak only when spoken to, and say as little as possible" $(1999,56)$.
} 
be publicly evaluated; students risk being wrong in front of their peers. Because students have had little practice with evaluating the validity of competing explanations, it is much safer to remain quiet than to make a comment that could be wrong or ask a question that demonstrates ignorance. At the same time that students may recognize their relative lack of experience and understanding of the political world around them, however, they still hold opinions about the best way to achieve the "good society." In our classes, for example, students often come to discussions of government problem solving with naive assumptions about cooperation and efficiency as the norm. Challenging those assumptions is cognitively (and emotionally) costly. Instead of simple facts and ready-made answers, students must engage in discussions of cultures, concepts, and issues that replace their (untried) convictions with complex and uncertain explanations. In the end, it is less costly to minimize uncertainty by focusing on the concepts (through memorization) at the expense of understanding and analysis.

The nature of many political science classes where incentives preclude many students from moving beyond acquisition and comprehension of a large number of abstract concepts makes the outcome of higher-level thinking less likely. Large class size and/or lecture-style delivery often means information flows in only one direction with little opportunity for students to participate in activities that help them learn how to evaluate and analyze information. Students focus most of their time on the numerous and complex concepts they need to master. Finally, disincentives for student participation mean that students play a passive role in the learning process. Although these factors may lead many to conclude that abandoning both large classes and lecture-style delivery, lack of participation and learning does not have to be the inevitable outcome. Educational psychology offers real solutions to the problems in these courses.

\section{The Case for an Interactive Classroom}


One-way communication often fails to promote higher-level thinking and fails to increase retention of information because 1) the principal (if not exclusive) use of the lecture often reaches only one kind of learner (primarily the aural learners) and does not accommodate other learning styles, 2) it reinforces passive attitudes and behaviors, regarding knowledge acquisition and comprehension, rather than that of analysis and evaluation, as the goals of education, and 3) it provides few situations that encourage students to play an active role in acquiring and applying knowledge (Williams 2003; Dev et al 2004).

As noted previously, one of the outcomes we hope to achieve with our students is literate conversation, in which they use concepts in analyzing and discussing critical questions in the discipline. However, as Leanmson points out, it is clear that "telling students what they need to know is one thing; doing something that will inspire them to become motivated and actually learn is quite another" (Leanmson 1999, 55).

One of the best ways professors can overcome these obstacles and achieve the goal of literate conversation is to design instruction that teaches to all types of learners (Lim 2003) and provides students with opportunities to work together. This instruction strategy provides incentives for greater participation and promotes greater ownership of the material covered. It also results in higher retention, because it helps students develop and use analysis and evaluation skills. The four types of learners we considered are activists (doers), reflectors (watchers), pragmatists (feelers), and theorists (thinkers) (Lim 2003; see also Gershkoff 2005). Instruction aimed at activists should be hands-on, trial-and-error activities that directly involve the students. Instruction aimed at reflectors should allow students to carefully observe different perspectives, gather information, and ask why. In designing instruction for pragmatists, the focus should be on technical problem-solving rather than interpersonal tasks. Finally, promoting learning for 
theorists often includes instruction that gives students the right answers rather than leaving them to explore randomly. When professors design instruction that teaches to all four types of learners, they are not only teaching to the strengths of different students, but they are also encouraging and facilitating students' progress through each of the four different ways of learning. This results in increased interaction between student and professor and especially between students (Fox and Ronkowski 1997; Brock and Cameron 1999; Gershkoff 2005).

Educational psychologists have found that students learn better when they cycle through all of the four learning styles rather than when they focus exclusively on one (Lim 2003). Lecture dominant content delivery may reach some learners, but it does not encourage even those learners to move toward activities that promote higher levels of learning. Specifically, it fails to solve the problem of students' focusing on memorizing concepts and avoiding highercost activities when lower-cost note taking yields the same result. For reflectors and theorists, the lecture style may provide different perspectives, encourage collection of information (note taking), and provide correct answers. On the other hand, lectures do not really encourage reflectors and theorists to ask why and cooperatively seek to answer that question. The lecture style often completely fails to address the learning styles of activists or pragmatists. For example, the lecture affords activists little opportunity to apply theory to practical situations or to participate in practical, cooperative activities where students can try out and test the theory. As with activists, there is often little space in a lecture-based course for pragmatists to deduce principles or theories or tap into their own experiences when the tempo of the lecturer determines and restricts information flow.

When instruction cycles through different learning styles, it provides effective active and cooperative learning experiences that promote deeper learning. In general, these experiences 
include 1) exposure to information and ideas; 2) experiences applying or interacting with information and ideas; and 3) opportunities for reflection on experience (Fink 2003, 106). An example of the cycling process that includes these three general types of experiences would be learning the basic principles of Duverger's Law.

- Watching: students listen to the professor present concepts and data related to electoral formula and party system.

- Thinking: students cooperatively develop their own hypotheses and evaluate how well the data supports those hypotheses.

- Doing: students cooperatively work through assignments that require them to apply what they have learned to real-world examples and make conclusions about the appropriateness of their hypotheses.

- Feeling: students work by themselves with the data and with textbook explanations to draw conclusions.

Designing instruction that involves more students can promote higher levels of student engagement with the material and retention in the learning process. It also goes a long way toward resolving the problems of (1) students' tendency to focus on solely lower level cognitive skills to master numerous and complex concepts, and (2) student disincentives to participate more actively in the learning process. The challenge now is to transfer those techniques to the context of the large classroom where higher student involvement and in-class cooperative activities may compromise the ability of the professor to adequately cover the material. Studies 
In an effort to significantly improve student engagement in two introductory courses we taught in 2004, we each implemented different interactive in-class voting systems. In Professor A's course, Introduction to Comparative Politics, students used a small, hand-held transmitter (voting device or "clicker") to cast their votes in two multi-day simulations. In Professor B's American Government and Politics course, students used a similar device for the entire term to take in-class quizzes, answer "poll" questions, and participate in other class activities. In both courses, student assessment of the technology and the learning activities was very positive.

For both case studies, we provide the following:

1. A brief course description

2. A review of the particular technology used

3. A description of how the technology was used

4. A discussion of the benefits of the technology

5. A summary of management issues and challenges encountered

6. A summary of the evaluation findings

\section{Course Descriptions}

Professor A taught Political Science 150, Introduction to Comparative Politics, during Winter Semester 2004. This course enrolled 140 students. Professor B taught Political Science 110, American Government and Politics, Summer Term 2004. There were 43 students enrolledin this course.

\section{Voting Technology Description}

In consultation with the University's Center for Instructional Design, A chose to use the H-ITT System for his Comparative Politics course (see http://www.h-itt.com). This system consists of an infrared transmitter for each student (See Figure 1) and a set of receivers 
positioned around the room (one receiver for every 40 students). The receivers are connected to each other and then to a laptop computer where the professor can see the results of student votes or answers. Those vote results can also be displayed on the screen at the front of the class. The software to view response data is free to those who adopt the technology for their courses.

\section{Figure 1 about here}

The transmitters cost $\$ 22.50$ each. The receivers, cabling, and power adapters for 140 students cost an additional $\$ 750$. The implementation of interactive voting technology in Political Science 150 was funded by an instructional research grant from the University's Center for Instructional Design. Consequently, students did not purchase their own voting devices (see below for management details).

To provide a comparison point in the evaluation of interactive voting technologies, B selected a different vendor-Turning Technologies (http://www.turningtechnologies.com) — to provide transmitters (see Figure 2), receivers, and software for his American Government course. Because B's course was designed to use the voting system every class session, students were required to purchase their own transmitters. These were bundled with the textbook for the course (American Government \& Politics Today, Schmidt, Shelley \& Bardes) and cost about \$20. Thomson Learning, the publisher of the text, has partnered with Turning Technologies to provide free receivers, adapters, and software to faculty members who adopt the technology (in connection with a Thomson textbook). ${ }^{5}$ The Turning Technologies software, TurningPoint, is

\footnotetext{
${ }^{5}$ This may be a limitation for those who would like to use a textbook not published by Thomson Learning. The authors did not explore that possibility with Turning Technologies.
} 
integrated with Microsoft Office, so quizzes and other questions can be displayed in PowerPoint, while student responses are captured in an Excel spreadsheet.

\section{Figure 2 about here}

\section{Voting Technology Implementation}

In the Comparative Politics course, the transmitters were used primarily during two multi-day classroom simulations: the constitutional convention and the coalition-building simulation. In order to trouble shoot possible problems with using the transmitters and to familiarize the students with the technology, B's teaching assistants issued each student a transmitter during the class prior to both simulations. Because of the size of the class, this was necessary so that the entire class time could be utilized for simulation activities on the days scheduled.. The transmitters were collected at the end of the simulation.

Similar to Ambrosio's constitutional design simulation (described in the April 2004 issue of $P S)$, the constitutional convention simulation requires students to develop a working constitution. The constitutional convention simulation usually takes about four 50-minute class periods. Students are given ethnic, religious, class, and geographic origin identities as well as other relevant background information at the beginning of the simulation. After meeting in ethnic groups to determine their group's overall priorities and strategies in three areas of the constitution (Elections, Executive-Legislative relations, and Local Autonomy), the groups appoint delegations to six subcommittees. The following class period, the delegations from each ethnic group meet in both subcommittees and full committee to consider all proposals relevant to their constitutional area and to construct proposals to introduce formally to the convention as a whole. The last two class periods are devoted to the meeting of the Constitutional Convention as a whole. During those last two class periods, students follow parliamentary procedure and 
present formal proposals to the convention. The students use the transmitters to register their votes for amendments to proposals and for proposals as a whole. Because each transmitter is uniquely numbered, the students can see their vote displayed on the screen at the front of the class once they have voted. At the end of each vote, the results are displayed on the screen.

The coalition-building simulation is based on the results of the Constitutional Convention. This simulation usually takes three 50-minute class periods. Retaining the same identities and building on the constitution they developed during the first simulation, students are assigned to political parties, in which they elect party leadership and develop a party platform. This takes place during the first and half of the second class period. Parties then present their platforms during the latter half of the second class period. An election is held at the beginning of the third class period. Following the election, the party with the most votes wins first opportunity to develop a viable governing coalition with a prime minister and a cabinet. Each party in the coalition must agree on three economic, social, and foreign policy issues. The students use the transmitters for "straw-polls" leading up to the election, for the election itself, and for the voting on the proposed coalition.

The availability of the results and the real-time speed at which they were delivered enabled students to better and more efficiently engage in analysis and evaluation-both in small groups and as a whole class. Rather than waiting for a hand count at each stage in the process of developing and voting on a constitution and of crafting a coalition, students could immediately evaluate how particular institutions and coalitions best served their "interests" as an ethnicity or class.

In the American Government course, as noted, each student purchased their own PRS device. Class meetings were of two kinds - traditional lectures and interactive 
lessons/simulations. In each case, students answered quiz questions, responded to opinion polls, or participated in live simulations, e.g. mock constitutional convention. Students also regularly offered their own questions, which the instructor put to their fellow class members using the Turning Technology software linked to PowerPoint. These activities and others involved all of the students' learning styles.

Each student's PRS device was uniquely numbered, so the professor could track individual responses throughout the semester. These responses were used to assess things like have the students had read the text before class, have the students recognized and understood key concepts, are the students paying attention, etc. In addition, instead of taking roll each day, the presence of response data for a given student on a given day verified student attendance in class. ${ }^{6}$

\section{Technology Benefits}

The use of the voting technology in both the Comparative Politics and the American Government classes provided a way to tap into the benefits of cooperative/problem-based learning activities. Through an online questionnaire of the students, we found that using the voting technology contributed positively to student motivation to participate, helped students learn and retain key concepts, and had a positive effect on student attitudes and perceptions about the class and their own learning. Finally (and most notably), using the voting technology increased student-student and student-professor interaction, which led students to exercise higher-level cognitive skills of analysis and evaluation.

Students noted that using the transmitters provided a significant motivation to participate in the simulations (See Table 1).

\footnotetext{
${ }^{6}$ Burnstein and Lederman report using "wireless keypad systems" for these and similar purposes (2003).
} 


\section{Table 1 about here}

In a large class, student participation is often limited to the few outspoken students. However, students indicated satisfaction in taking a stand with the transmitter while still remaining anonymous. One student noted: "When voting is done by a show of hands, sometimes social desirability prevents students from voting their true conscience (perhaps they are afraid of being the lone dissenting vote)." Another student agreed, stating that using the transmitters "helped everyone to express their true opinion." One student even noted that the simulation "wouldn'g have been taken as seriously if the technology wasn't a part of it." Students also noted satisfaction with the instantaneous display of voting results. One student stated, "because the results of our participation were available immediately, we could be more responsive to the group sentiment." ${ }^{, 7}$ Another student noted that using the transmitters during the simulation "helped me pay attention more because I knew I would be participating." Overall, students felt that the use of the transmitters made the simulation "more real," thereby increasing their desire to participate.

In addition to contributing to student willingness to participate, students also noted that using the transmitters during the simulation helped them learn and retain key concepts discussed

\footnotetext{
${ }^{7}$ When A conducted this simulation in the past without the voting transmitters, students often expressed frustration with the inaccuracy and time demands of a hand count and with the time it took to tally vote results. In an online questionnaire after using the voting technology, students reported that "the 'voting device' really sped things along. It was quicker than counting hands or writing votes. It also added to my feeling of involvement." Another student concurred noting that "the voting process did not take up a lot of time from the debate."
} 
earlier in the class. One student noted that using the transmitters in the simulations "made me want to know more, to understand concepts better, so that I could actively participate." Another student added that using the transmitters during the simulation "helps me look at the form of government in a different way" and "understand how so many countries could have so many different governments." For many students, the role of party politics as it relates to parliamentary and presidential systems, electoral formula, district magnitude, electoral thresholds, centralization and decentralization, and so on remain abstract and unimportant. Discussing the practical outcomes of alternative constitutional design scenarios in the context of a "real" country, assessing support through voting on those alternatives, and predicting success or failure of the final constitution dramatically improved the students' understanding both of the constitutional design process (see Table 2) and the role of the legislative branch (see Table 3).

Table 2 about here

\section{Table 3 about here}

In addition to issues of participation and retention, using the voting technology in simulations and other discussions helped the professor teach to all four learning styles. This, in turn, contributed positively to the cooperative learning atmosphere of the classroom. As most instructors traditionally do, B periodically stops at natural break points in a class meeting to ask students if they have any questions about material he has just covered. The typical response is no response. However, when he used the interactive voting technology to ask students specific "quiz" questions about what they just heard and discussed, the classroom culture changed significantly. When B saw empirical data suggesting that a large number of students did not understand a concept he had just explained, he was able to go back and try another approach to the subject matter that would engage students with other learning styles who needed to see the 
material written down or addressed in a more hands-on fashion. Moreover, when students saw that they were not alone in misunderstanding a particular concept, they were much less shy about asking clarifying questions. By putting "mastery check" or comprehension questions to the students and displaying the class results on the screen, formative evaluation and timely feedback became a much more regular, authentic and valuable part of the course.

The most significant benefit of using the voting technology was deeper, more meaningful discussion of issues and controversies. When discussing difficult ideas or problems, several lessthan-optimal scenarios often play out. A few outspoken students state their opinions loudly and forcefully, making other students uncomfortable or unwilling to share their views. Other students have opinions but lack the confidence or conviction to express them. The net result is that a few vocal students dominate the conversation or, just as frequently, no one says anything at all (the rational student model). However, when students are required to answer opinion poll questions in class using the interactive voting technology, there is a perceptible change in the culture of the class. Having made a commitment to their opinion on the "big screen," students are generally more willing to vocalize those opinions. Particularly, those with minority opinions seem more willing to express their views vocally when they see that there are others who share their views. Once the results of a poll question were visible to the class, B would frequently ask questions such as: "Would someone who chose option 'B' be willing to explain their point of view?" This direct invitation in response to an explicitly expressed opinion elicited more comments and discussion than is typical. Even those students who did not vocalize their opinions noted satisfaction with using the technology: "I really liked having a say. Even though I wasn't very vocal I was still able to express my opinion." Using the technology in this way also opens the door for more critical evaluation and analysis to take place. 
Overall, these results remain inconclusive (they are largely anecdotal and qualitative) and need further, more systematic tests. The initial study indicates, however, that using the voting technology brings significant pedagogical payoffs for political science classes (both large and smaller). First, using the voting technology in the class leads to the involvement of many different learning styles because it provides students with the opportunity to encounter the material in ways that they learn best. Second, the material becomes more "real" and more relevant to the students, thus promoting greater participation and retention. Third, the voting technology helps students learn and practice higher-level thinking skills by involving more students and by encouragingand facilitating more thoughtful involvement. Future research in this area should more carefully explore the differences in engagement and participation between classes that use interactive voting technology and those that do not.

\section{Management Issues \& Challenges}

The technology itself presented the primary management issues and challenges. After using both systems, we found the Turning Technologies system better promoted the goal of increased classroom interaction. Certainly, neither system was without flaws. In fact, there were several challenges that both A and B faced in using the voting technology in the classroom. One of those challenges was the additional time required. Many of the classrooms at _ University are designated as "Tec Rooms," meaning that there is a technology podium at the front of the room with a computer, a VCR, and a DVD player. These classrooms are also equipped with projectors and sound systems. Given technical difficulties associated with installing both the H-ITT and the TurningPoint software on a Tec Room computer, A and B both opted to bring a laptop computer (along with the receivers) to class each week, connecting the laptops to the projector in the room. Additionally, the receivers had to be set up at the beginning and taken down at the end of each 
class period. For B's class, this generally took about five minutes at the beginning of class and five minutes at the end of class, and Mott and his teaching assistant could do it. However, for A's class of 140 students, the University's Center for Instructional Design staff needed 15 minutes before and after class to set up, take down, and trouble-shoot the required equipment. A and B are still exploring with the university the possibility of having the hardware permanently installed in a classroom.

Although it did not ameliorate all potential problems associated with student use of the transmitters, we found that requiring students to purchase their own transmitter and bring it to class each day worked more effectively than issuing the students the transmitters for a few classes, collecting them and reissuing them later in the semester for the next simulation. This was true mostly due to the time required to issue and gather the transmitters. In a large class like A's, it took at least twenty minutes to issue transmitters (and about the same amount of time to collect them and track down transmitters in the possession of delinquent students). In addition, both times A issued the transmitters, teaching assistants had to enter the student's name and transmitter number in an Excel spreadsheet (because of the time required to enter that information and the additional time required to manually paste vote results into Excel, A opted to simply use the transmitters to facilitate voting during the simulations). On the other hand, B's requirement that all students purchase their voting device meant that associating names with voting devices took little classroom time. (At the beginning of the semester, each student emailed his or her device number to the teaching assistant, who made a master class list associating students with their devices.)

One predictable challenge both A and B faced was students coming to class without their voting transmitter. Both A and B had "loaner" transmitters that students could borrow for a class 
period. This posed a relatively minor problem in A's course, since the students used the transmitter only for simulation votes (because A did not hold students accountable to vote, some students who forgot their transmitters simply did not vote). For B, "forgotten transmitters" created different problems. To associate the students' responses on that day with their other responses during the term required a manual "cut and paste" of their data for that day from the loaner device ID to their personal device ID in the class spreadsheet. (B delegated this duty to a teaching assistant.) More problematic, however, were two instances in which students lost their devices. Because students had been warned early in the semester that they were responsible for their voting devices and that the devices would be required to participate in class every day, these students had to purchase new ones so they could continue to participate in the course. In promoting greater classroom interaction and student assessment, Turning Technology outshone H-ITT. Because Turning Technology is integrated with Microsoft Office, student responses are automatically linked to the specific question, recorded, and captured for future display and/or analysis in Excel, Word, and PowerPoint. Responses to questions using the H-ITT system must be manually pasted into Excel. Turning Technology also offers a number of customizable PowerPoint templates. In the heat of classroom discussion or simulation, this facilitates crafting questions "on the fly" and storing them for future analysis and could be used to stimulate further discussion and greater participation in that discussion. A found that he could also craft real-time questions but had to switch back and forth between H-ITT and PowerPoint (as students voted, they couldn't view both the question and their responses). Without additional effort, it was impossible to link the voting results with the questions. Finally, Turning Technology allowed for comparison of voting results before and after discussion of critical issues. Students seemed especially interested in assessing both the level of class comprehension 
in mastering different concepts and in changing opinions about issues discussed in the class. Although it remains untested, B noticed increased engagement in class discussion and retention of concepts discussed.

\section{Evaluation Results}

The Introduction to Comparative Politics class seeks to promote critical thinking about political events that affect the lives of the students. This means students must master a set of basic concepts and connect those concepts to "the world out there." Certainly, the results we are reporting here need to be compared with a similar class that did not use the voting technology. However as noted earlier, $68 \%$ of the students agreed that using the transmitter "improved my understanding of the constitutional design process." In addition, 63\% agreed that "the lessons using" the transmitter "effectively taught the role of the legislative branch."

One of the most important objectives for American Government and Politics (Political Science 110) is that students feel more prepared to be effective citizens. In particular, B attempts to ameliorate many students' natural cynicism by instilling enthusiasm and realistic optimism about their abilities as citizens. While it is impossible to know how these results would differ if students had not used interactive voting technology in this course, the results are quite positive. More than $90 \%$ of the students in the course indicated that they felt "more informed and prepared" to participate effectively as a citizen after this course (see Table 4). Additionally, more than two-thirds of those in the class indicated that they felt more optimistic about their role as citizens after the class than they did before (see Table 5).

Table 4 about here

Table 5 about here

While these results are encouraging, there is no basis for comparison to determine the relative impact of the voting technology on their attitudes. (As we noted previously, future 
research should explore this question.) In this case, we measured students' perceptions of the course and their own learning. A striking $91.2 \%$ of the students indicated the course was "more enjoyable" because of the voting technology (see Table 6), and 94.1\% said the voting technology stimulated "more discussion than in other classes I've been in" (see Table 7). With regard to direct impact on learning and engagement, 71.9\% (see Table 8) believed the technology helped them "learn more in this class" and 93.8\% (see Table 9) indicated that the voting technology helped them "pay more attention and participate more in class."

\section{Conclusion}

\section{Table 6 about here Table 7 about here Table 8 about here Table 9 about here}

Leamnson notes that "somehow we must provide discussions, assignments, and other activities that cannot be carried out without reflective thought about the content" (Leamnson, p. 60). On the other hand, the realities of many political science courses make achieving Leamnson's maxim difficult. Specifically, student anonymity, the requirement of mastering many complex concepts, and disincentives for student participation often combine to discourage reflective thought. Based on the two case studies, we have presented, however, we are confident that combining interactive voting technology with cooperative learning activities in political science courses facilitates that kind of reflective thought. Specifically, the students are more engaged, formative feedback is a more regular and natural part of instruction, students feel more personally involved and invested in the learning process, and students better retain concepts they learn. In short, cooperative learning activities combined with interactive voting technology leads students to develop higher-level thinking skills. 
As we noted, the studies reported here are limited. Additional research, based on experimental or quasi-experimental studies, would add significantly to our understanding of effective pedagogy and learning. We encourage individual instructors and departments to consider adoption and implementation of interactive classroom technology. We also encourage instructors to formally evaluate the effectiveness of that technology so we can continue to learn about effective teaching \& learning practices in introductory political science courses.

\section{References}

Ambrosio, Thomas. 2004. "Bringing Ethnic Conflict into the Classroom: A Student-Centered Simulation of Multiethnic Politics.” PS: Political Science 37 (April): 285-289.

Bardes, Barbara A., Steffen W. Schmidt, and Mack C. Shelley. 2003. American Government \& Politics Today: The Essentials, $11^{\text {th }}$ edition. Wadsworth Publishing.

Brock, Kathy L. and Beverly J. Cameron. 1999. "Enlivening Political Science Courses with Kolb’s Learning Preference Model.” PS: Political Science 32 (June): 251-256.

Burnstein, Ray A. and Leon M. Lederman. 2003. "Comparison of Different Commercial Wireless Keypad Systems.” The Physics Teacher, 41 (May): 272-275.

Cromwell, L. 1993. "Active learning in the classroom: Putting theory into practice." Experiential Learning Quarterly 18(3): 18-23.

Dewey, John. 1963. Experience and Education. New York: Collier

Ewell, Peter T. 1997. “Organizing for Learning: A New Imperative,” in 1997 AAHE Bulletin. AAHE.

Fink, L.D. 2003. Creating significant learning experiences: An integrated approach to designing college courses. San Fransisco: Jossey-Bass, p. 106. 
Fox, Richard L. and Shirley A. Ronkowski. 1997. "Learning Styles of Political Science Students.” PS: Political Science 30 (December): 732-737.

Gershkoff, Amy R. 2005. "Multiple Methods, More Success: How to Help Students of All Learning Styles Succeed in Quantitative Political Analysis Courses.” PS: Political Science 38 (April): 299-304.

Green, Andrew and William Rose. 1996. “The Professor's Dream: Getting Students to Talk and Read Intelligently.” PS: Political Science 29 (December): 687-690.

Halfacre, Angela C., Katharine A. Owens, Katherine S. Zimmerman, and Zachary H. Hart. 2004. "The Green Building Project: Promoting Political Science Learning through a Collaborative Research Approach.” PS: Political Science 37 (April):297-302.

Huerta, Juan Carlos. 2004. “Do Learning Communities Make a Difference?” PS: Political Science 37 (April): 291-296.

Leanmson, Robert. 1999. Thinking About Teaching and Learning: Developing Habits of Learning with First Year College and University Students. Stylus: Sterling, VA. Lim, Lisa. 2003. "Successful Learning: Going Cycling with Learning Styles." http://www.cdtl.nus.edu.sg/success/s127.htm (September 22, 2004)

Dev, Parvati, Melissa Enriquez, Todd Grappone, Miriam M. Martinez, Anil S. Menon, and Shannon Moffett. 2004. “Audience Response Made Easy: Using Personal Digital Assistants as a Classroom Polling Tool," Journal of American Medical Information Association. (11): 217-220.

Payerhin, Marek. 2003. "Have Case, Will Travel: Taking Political Science On (and Off) the Road." PS: Political Science 36 (July): 441-445. 
Steinert, Yvonne and Linda S. Snell. 1999. "Interactive Lecturing: Strategies for Increasing Participation in Large Group Presentations," Medical Teacher 21 (January): 37 - 42. Williams, Jeremy B. 2003. "Learning by Remote Control: Exploring the Use of an Audience Response System as a Vehicle for Content Delivery," Proceedings of the 20th Annual Conference of the Australasian Society for Computers in Learning in Tertiary Education (ASCILITE) Brisbane, Australia, 7-10 December, http://www.ascilite.org.au/conferences/adelaide03/docs/pdf/739.pdf

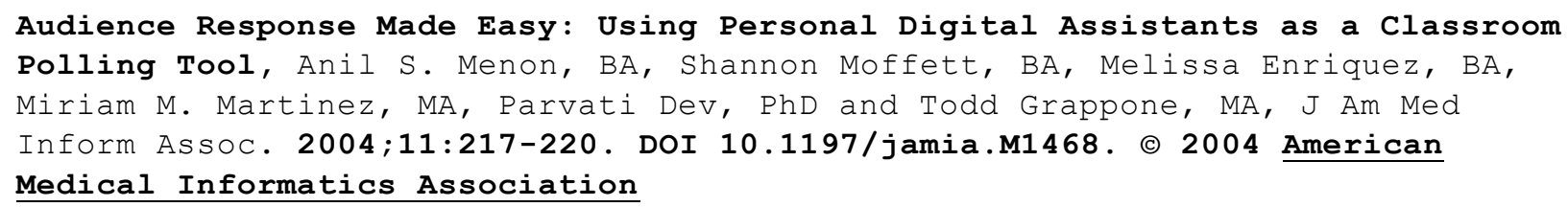




\section{$\odot \odot \odot \odot \odot \odot \odot$}

Figure 1.

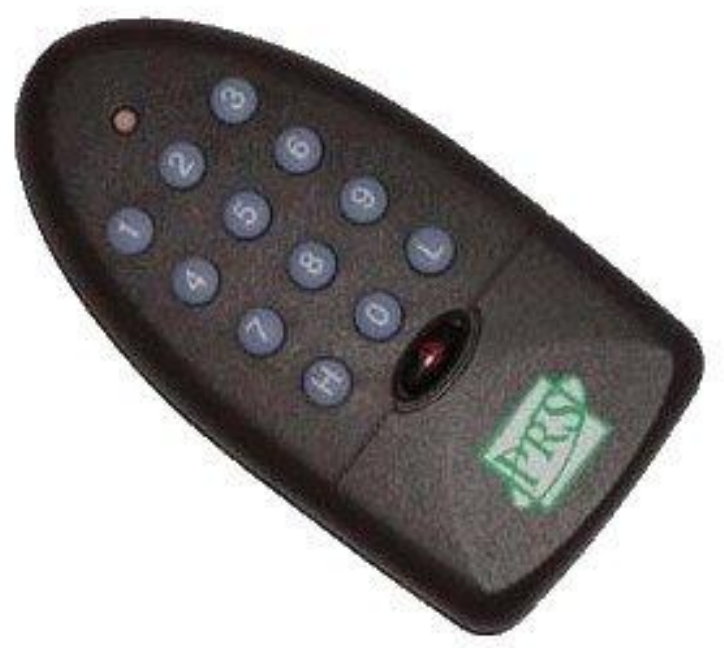

Figure 2.

Table 1. Because of the way "the voting device" was used I participated more in the classroom. $(n=82)$

\begin{tabular}{|l|l|l|l|}
\hline & Frequency & Percent & Cumulative \\
\hline Strongly Agree & 28 & 34.2 & 34.2 \\
\hline Agree & 43 & 52.4 & 86.6 \\
\hline Neutral & 5 & 6.1 & 92.7 \\
\hline Disagree & 5 & 6.1 & 98.8 \\
\hline Strongly Disagree & 1 & 1.2 & 100.0 \\
\hline TOTAL & 82 & 100 & 100.0 \\
\hline
\end{tabular}

Table 2. Using "the voting device" improved my understanding of the constitutional design process. $(n=82)$

\begin{tabular}{|l|l|l|l|}
\hline & Frequency & Percent & Cumulative \\
\hline Strongly Agree & 14 & 17.1 & 17.1 \\
\hline Agree & 52 & 63.4 & 80.5 \\
\hline Neutral & 15 & 18.3 & 98.8 \\
\hline Disagree & 0 & 0.0 & 98.8 \\
\hline Strongly Disagree & 1 & 1.2 & 100.0 \\
\hline TOTAL & 82 & 100.0 & 100.0 \\
\hline
\end{tabular}


Table 3. The lessons using "the voting device" effectively taught the role of the legislative branch. $(n=82)$

\begin{tabular}{|l|l|l|l|}
\hline & Frequency & Percent & Cumulative \\
\hline Strongly Agree & 17 & 20.7 & 20.7 \\
\hline Agree & 46 & 56.1 & 76.8 \\
\hline Neutral & 15 & 18.3 & 95.1 \\
\hline Disagree & 3 & 3.7 & 98.8 \\
\hline Strongly Disagree & 1 & 1.2 & 100.0 \\
\hline TOTAL & 82 & 100.0 & 100.0 \\
\hline
\end{tabular}

Table 4. Do you agree or disagree with this statement: "I feel more informed and prepared to be an effective citizen after participating in this course"? $(n=27)$

\begin{tabular}{|l|c|c|c|}
\cline { 2 - 4 } \multicolumn{1}{c|}{} & Frequency & Percent & Cumulative \\
\hline Strongly Agree & 20 & 74.1 & 74.1 \\
\hline Agree Somewhat & 5 & 18.5 & 92.6 \\
\hline Disagree Somewhat & 2 & 7.4 & 100.0 \\
\hline Strongly Disagree & 0 & 0 & 100.0 \\
\hline TOTAL & 27 & 100.0 & 100.0 \\
\hline
\end{tabular}

Table 5. Compared to how you felt before this course began, how do you feel about the role of citizens in the American political system? $(n=34)$

\begin{tabular}{|l|c|c|c|}
\cline { 2 - 4 } \multicolumn{1}{c|}{} & Frequency & Percent & Cumulative \\
\hline More Optimistic & 22 & 64.7 & 64.7 \\
\hline No Change & 10 & 29.4 & 94.1 \\
\hline Less Optimistic & 2 & 5.9 & 100.0 \\
\hline TOTAL & 34 & 100.0 & 100.0 \\
\hline
\end{tabular}

Table 6. Do you agree or disagree with the following statement? "The PRS technology made this course more enjoyable." $(n=34)$

\begin{tabular}{|l|c|c|c|}
\cline { 2 - 4 } \multicolumn{1}{c|}{} & Frequency & Percent & Cumulative \\
\hline Strongly Agree & 18 & 52.9 & 52.9 \\
\hline Agree Somewhat & 13 & 38.2 & 91.2 \\
\hline Disagree Somewhat & 1 & 2.9 & 94.1 \\
\hline Strongly Disagree & 2 & 5.9 & 100.0 \\
\hline TOTAL & 34 & 100.0 & 100.0 \\
\hline
\end{tabular}

Table 7. Do you agree or disagree with this statement? "The PRS technology helped stimulate more discussion than in other classes l've been in." $(n=34)$

\begin{tabular}{|l|c|c|c|}
\cline { 2 - 4 } \multicolumn{1}{c|}{} & Frequency & Percent & Cumulative \\
\hline Strongly Agree & 18 & 52.9 & 52.9 \\
\hline Agree Somewhat & 14 & 41.2 & 94.1 \\
\hline
\end{tabular}




\begin{tabular}{|l|c|c|c|}
\hline Disagree Somewhat & 1 & 2.9 & 97.1 \\
\hline Strongly Disagree & 1 & 2.9 & 100.0 \\
\hline TOTAL & 34 & 100.0 & 100.0 \\
\hline
\end{tabular}

Table 8. Do you agree or disagree with this statement? "The PRS technology helped me learn more in this class." $(n=32)$

\begin{tabular}{|l|c|c|c|}
\cline { 2 - 4 } \multicolumn{1}{c|}{} & Frequency & Percent & Cumulative \\
\hline Strongly Agree & 7 & 21.9 & 21.9 \\
\hline Agree Somewhat & 16 & 50.0 & 71.9 \\
\hline Disagree Somewhat & 6 & 18.8 & 90.6 \\
\hline Strongly Disagree & 3 & 9.4 & 100.0 \\
\hline TOTAL & 32 & 100.0 & 100.0 \\
\hline
\end{tabular}

Table 9. Do you agree or disagree with this statement? "The PRS technology helped me pay more attention and participate more in class." $(n=32)$

\begin{tabular}{|l|c|c|c|}
\cline { 2 - 4 } \multicolumn{1}{c|}{} & Frequency & Percent & Cumulative \\
\hline Strongly Agree & 19 & 59.4 & 59.4 \\
\hline Agree Somewhat & 11 & 34.4 & 93.8 \\
\hline Disagree Somewhat & 2 & 6.3 & 100.0 \\
\hline Strongly Disagree & 0 & 0.0 & 100.0 \\
\hline TOTAL & 32 & 100.0 & 100.0 \\
\hline
\end{tabular}

